\title{
Hemagglutinin protein of Asian strains of human influenza virus A H1N1 binds to sialic acid - a major component of human airway receptors
}

\author{
K.H. Chua ${ }^{1}$ and H.C. Chai ${ }^{2}$ \\ ${ }^{1}$ Department of Molecular Medicine, Faculty of Medicine, \\ University of Malaya, Kuala Lumpur, Malaysia \\ ${ }^{2}$ School of Medicine and Health Sciences, \\ Monash University, Sunway Campus, Selangor, Malaysia
}

Corresponding author: K.H. Chua

E-mail:khchua@um.edu.my

Genet. Mol. Res. 11 (1): 636-643 (2012)

Received March 21, 2011

Accepted October 27, 2011

Published March 16, 2012

DOI http://dx.doi.org/10.4238/2012.March.16.1

\begin{abstract}
Hemagglutinin (HA) protein plays an important role in binding the influenza virus to infected cells and therefore mediates infection. Deposited HA sequences of 86 Asian strains of influenza A $(\mathrm{H} 1 \mathrm{~N} 1)$ viruses during the first outbreak were obtained from the NCBI database and compared. Interaction of the HA protein of influenza A (H1N1) virus with the human sialic acid receptor was also studied using bioinformatics. Overall, not more than three singlepoint amino acid variants/changes were observed in the HA protein region of influenza $A(\mathrm{H} 1 \mathrm{~N} 1)$ virus from Asian countries when a selected group sequence comparison was made. The bioinformatics
\end{abstract}


study showed that the HA protein of influenza A (H1N1) binds to the sialic acid receptor in human airway receptors, possibly key to airborne infection in humans.

Key words: H1N1; Molecular simulation; Receptor; Sialic acid

\section{INTRODUCTION}

The A (H1N1) pandemic, also commonly referred to as "swine flu", is a global outbreak of a new strain of influenza A virus subtype H1N1, identified in April 2009. Within 5 months after its emergence, infection cases of more than 290,000 with associated deaths of 3486 were reported worldwide, and this number actually understated the real number of cases (Swedish et al., 2010). In Malaysia, as of January 30, 2010, 12,389 infection and 77 death cases have been reported. The flu began in Mexico and Southern California (CDC, 2009). The virus spreads from coughs and sneezes or by touching contaminated surfaces and then touching the nose and mouth (Brankston et al., 2007). The illness manifestations are similar to those of seasonal flu and include fever, cough, sore throat, runny nose, body aches, chills and fatigue, and diarrhea and vomiting have also been reported in some cases. People infected with this virus may be contagious from one day before they develop symptoms to up to 7 days after they get sick (Carrat et al., 2008). Antiviral drugs that are recommended for use against swine influenza $A$ (H1N1) virus are oseltamivir (Tamiflu) and zanamivir (Relenza). As for the vaccine, the influenza A (H1N1) 2009 monovalent vaccine is used and as of January 2, 2010, an estimated 20.3\% of the U.S. population (61 million persons) had been vaccinated (CDC, 2010). Malaysia also received 46,000 and 78,000 doses of vaccine in November 2009 and January 2010, respectively. Actions such as containments, quarantines, airport health screenings, school closures, etc., have been undertaken to prevent the spread of the virus and to contain the infection.

The virus isolated from patients in the United States was found to be made up of genetic elements from four different flu viruses - North American Mexican influenza, North American avian influenza, human influenza, and swine influenza virus typically found in Asia and Europe (Novel Swine-Origin Influenza A (H1N1) Virus Investigation Team, 2009). This new strain appears to be a result of reassortment of all four different strains of subtype H1N1. Full-length viral genome sequences from around the world have been published and made available in public-access databases. Influenza A is a single-stranded RNA virus with eight different segments. Six segments of the swine influenza A (H1N1) virus are related to swine viruses from North America and the other two [neuraminidase (NA) and matrix protein (M)] from swine viruses isolated in Europe/Asia (Trifonov et al., 2009a). The segments coding for the polymerase complex (PB1, PB2, PA, PB1-F2), HA, nuclear protein (NP), and nonstructural proteins (NS1, NS2) show high similarity with the swine H1N2 influenza A viruses isolated in North America in the late 1990s. However, the segments coding for the NA and the M1, M2 are distantly related to European swine influenza A virus strain from 1992, with $94.4 \%$ similarity at the nucleotide level (Trifonov et al., 2009b). Experts are concerned that the new influenza A (H1N1) virus could mutate over the coming months, noting that the unstable virus could mix and swap genetic material when exposed to other viruses, especially seasonal flu and H5N1 (bird flu) viruses (Novel 
Swine-Origin Influenza A (H1N1) Virus Investigation Team, 2009). Fortunately, until July 2009, the swine flu virus has not mutated to become more dangerous (Turner et al., 2009). However, close monitoring of the viral changes is being undertaken as the virus continues to spread extensively around the globe.

In general, HA is an important property of influenza viruses, whereby it is responsible for initial infection in humans through airway receptor attachment. It binds influenza viruses to SA-containing receptors of infected cells and allows the entry of the viral genome into the infected cells by causing the fusion of host endosomal membrane with the viral membrane (White et al., 1997). In this study, we narrowed down the scope and aimed to compare the GenBank-deposited HA protein of new H1N1 viruses from Asian countries to search for possible mutations/variants in the HA protein of this human flu virus during this pandemic. In addition, bioinformatics molecular simulation was also performed to illustrate the binding of the HA protein to sialic acid (SA), a human airway receptor determinant.

\section{MATERIAL AND METHODS}

A total of 86 HA protein sequences of human pandemic (H1N1) 2009 viruses from Asian countries during the first outbreak were recruited from Influenza Virus Resource, National Center for Biotechnology Information (NCBI, 2009) (Table 1). An intensive multiple gene sequence alignment was carried out on the full-length HA protein sequence of influenza virus A H1N1. The consensus sequence was obtained and further simulated through homology modeling using SWISS-MODEL server (Guex and Peitsch, 1997; Schwede et al., 2003; Arnold et al., 2006). This model served as the target receptor protein. The SA structure was obtained from a protein databank under PDB accession number IJSO and served as the input ligand. Docking was carried out using ZDOCK (Discovery Studio 2.1).

\section{RESULTS}

The multiple gene sequence alignment results indicated that the HA protein was almost fully conserved among all 86 HA sequences of the Asian human pandemic (H1N1) 2009 viruses obtained from the Influenza Virus Resource, NCBI. Not more than three single-point amino acid changes were observed in the HA protein of these influenza A

(H1N1) viruses (Table 1). A few deleted amino acid sequences at the 5'- and 3'-end of these $86 \mathrm{HA}$ sequences were not considered mutation points in this study, because they could be due to incomplete sequencing results. Generally, two fragmented or monomer of HA protein models were obtained with the SWISS MODEL, using 1ruyH and 1ru7D as the templates; this was done to maintain the similarity as high as 84.52 and $94.5 \%$, respectively. Both HA models were subjected to docking using Discovery Studio 2.1 with ZRANK, and the top view of the docking results is shown in Figure 1. The SA model, representing the human type receptor, is clearly seen to form a stable complex with the HA protein of the influenza $A(\mathrm{H} 1 \mathrm{~N} 1)$ virus. A further insight analysis demonstrated that o-SA binds to 3 amino acids (GLY357, TRP358 and THR359) of the monomer of the HA protein (Figure 2) and that they are conserved in all 86 samples analyzed. 
Table 1. Mutations/variations detected in HA protein of human influenza virus A (H1N1) in Asian countries.

\begin{tabular}{|c|c|c|c|}
\hline Accession & Country & Year & Mutations/variations \\
\hline ACU29979 & Taiwan & $2009 / 05 / 19$ & T14A, S220T \\
\hline ACU29989 & Taiwan & $2009 / 05 / 22$ & S220T \\
\hline ACU29999 & Taiwan & $2009 / 05 / 22$ & $\mathrm{~S} 220 \mathrm{~T}$ \\
\hline ACU30009 & Taiwan & $2009 / 05 / 28$ & $\mathrm{~K} 2 \mathrm{E}, \mathrm{N} 557 \mathrm{G}, \mathrm{Q} 310 \mathrm{H}$ \\
\hline ACU30019 & Taiwan & $2009 / 05 / 30$ & $\mathrm{~S} 220 \mathrm{~T}$ \\
\hline ACR38877 & China & $2009 / 05 / 10$ & K2E, Q310H, K419T \\
\hline ACR46986 & Japan & 2009 & - \\
\hline ACR46987 & Japan & 2009 & $\mathrm{~N} 387 \mathrm{~K}$ \\
\hline ACR46988 & Japan & $2009 / 05 / 17$ & - \\
\hline ACR46989 & Japan & $2009 / 05 / 17$ & - \\
\hline ACR46990 & Japan & 2009 & - \\
\hline ACR46991 & Japan & $2009 / 05 / 16$ & V169I \\
\hline ACR46992 & Japan & $2009 / 05 / 16$ & - \\
\hline ACR46993 & Japan & $2009 / 05 / 16$ & - \\
\hline ACR46994 & Japan & $2009 / 05 / 17$ & - \\
\hline ACR49236 & China & $2009 / 05 / 17$ & - \\
\hline ACR54002 & China & $2009 / 05 / 21$ & - \\
\hline ACR54045 & China & $2009 / 05 / 29$ & S220T \\
\hline ACT79624 & China & $2009 / 06 / 06$ & Q310H \\
\hline ACT79625 & China & $2009 / 05 / 28$ & A151T, S220T, V428I, E447K \\
\hline ACU13122 & China & $2009 / 06 / 17$ & L49I \\
\hline ACU13129 & China & $2009 / 06 / 29$ & S220T, D219E, K412E \\
\hline ACU27041 & China & $2009 / 06 / 13$ & - \\
\hline BAH95823 & Japan & $2009 / 06 / 03$ & Y323H \\
\hline BAH95824 & Japan & $2009 / 05 / 21$ & - \\
\hline ACQ99682 & Thailand & $2009 / 05$ & $\mathrm{I} 421 \mathrm{M}$ \\
\hline ACR01014 & Thailand & 2009 & $\mathrm{I} 421 \mathrm{M}$ \\
\hline ACR78154 & Philippines & $2009 / 05 / 23$ & S220T \\
\hline ACR78158 & Philippines & $2009 / 05 / 20$ & L49I \\
\hline ACR78164 & Philippines & $2009 / 05 / 25$ & $\mathrm{~S} 220 \mathrm{~T}$ \\
\hline ACR78165 & Philippines & $2009 / 05 / 25$ & $\mathrm{H} 313 \mathrm{Y}$ \\
\hline ACR83538 & China & $2009 / 05 / 29$ & S220T, Q352L \\
\hline ACS27780 & China & $2009 / 05 / 24$ & S220T, V428I \\
\hline ACS 27787 & China & $2009 / 05 / 31$ & S220T \\
\hline ACS92569 & Japan & $2009 / 06 / 07$ & S100P, A214T, V338I \\
\hline ACS92579 & Japan & $2009 / 06 / 07$ & S100P, S220T, V338I \\
\hline ACS92589 & Japan & $2009 / 06 / 02$ & - \\
\hline ACS92600 & Japan & $2009 / 06 / 16$ & S202N \\
\hline АCT66162 & Singapore & $2009 / 06 / 30$ & K2E, Q121H \\
\hline ACT67255 & Japan & 2009 & S220T \\
\hline ACU56931 & Kazakhstan & 2009 & S220T, D219E \\
\hline АCT79133 & Japan & $2009 / 06 / 29$ & S220T, T249K \\
\hline ACQ84451 & South Korea & $2009 / 05 / 02$ & - \\
\hline ACR54047 & China & $2009 / 05 / 18$ & V520I \\
\hline ACR54964 & China & $2009 / 05 / 23$ & S220T, T408I \\
\hline ACR54974 & China & $2009 / 05 / 23$ & S220T, V428I, V520I \\
\hline ACR54984 & China & $2009 / 05 / 22$ & $\mathrm{~S} 220 \mathrm{~T}$ \\
\hline ACR54994 & China & $2009 / 05 / 15$ & - \\
\hline ACR55004 & China & $2009 / 05 / 20$ & - \\
\hline ACR67244 & China & $2009 / 05 / 27$ & S220T \\
\hline ACR67254 & China & $2009 / 05 / 23$ & A278V \\
\hline ACT10316 & Hong Kong & $2009 / 06 / 11$ & S220T, D219E, P314S \\
\hline ACT21941 & China & $2009 / 06$ & L49I, Q240R \\
\hline ACT22031 & Japan & $2009 / 06 / 11$ & S220T \\
\hline ACT22032 & Japan & $2009 / 06 / 23$ & S220T \\
\hline ACT22033 & Japan & $2009 / 06 / 09$ & S220T \\
\hline ACT22034 & Japan & $2009 / 06 / 18$ & $\mathrm{~S} 220 \mathrm{~T}$ \\
\hline ACT22035 & Japan & $2009 / 06 / 13$ & S100P, A214T, V338I \\
\hline ACT22036 & Japan & 2009 & V169I \\
\hline ACT22037 & Japan & $2009 / 06 / 11$ & S220T, D219E \\
\hline ACT22038 & Japan & $2009 / 06 / 16$ & S202N \\
\hline ACT 21572 & Israel & $2009 / 04$ & L49I, D291E \\
\hline
\end{tabular}

Continued on next page 


\begin{tabular}{llll}
\multicolumn{1}{c}{ Table 1. Continued. } & \multicolumn{1}{c}{} & \\
\hline Accession & Country & Year & Mutations/variations \\
\hline ACT21579 & Israel & $2009 / 04$ & L49I, D291E \\
ACT21584 & Israel & $2009 / 04$ & - \\
ACR09395 & Japan & $2009 / 05 / 08$ & - \\
ACR09396 & Japan & $2009 / 05 / 08$ & - \\
ACR32986 & China & $2009 / 05 / 10$ & L49I \\
ACR15758 & Israel & $2009 / 04$ & R450K \\
ACR18920 & Hong Kong & $2009 / 04 / 30$ & - \\
ACR23302 & Thailand & $2009 / 05 / 06$ & I421M \\
ACR32998 & China & $2009 / 05 / 16$ & - \\
ACS34705 & China & $2009 / 06 / 13$ & - \\
ACS34966 & Japan & $2009 / 05 / 18$ & - \\
ACS34967 & Japan & $2009 / 05 / 21$ & L329S, N387K \\
ACS34968 & Japan & $2009 / 05 / 22$ & T99S, T258I \\
ACS36632 & Japan & $2009 / 05 / 21$ & N387K \\
ACS36645 & China & $2009 / 05 / 18$ & A158T, V520I, N472S \\
ACS45017 & China & $2009 / 06 / 18$ & R222K, I527V \\
ACS54259 & Japan & $2009 / 06 / 07$ & S100P, A214T, V338I \\
ACS54260 & Japan & $2009 / 05 / 19$ & - \\
ACS54261 & Japan & $2009 / 06 / 06$ & S220T \\
ACS54262 & Japan & $2009 / 06 / 02$ & K2E, V149I, Q310H \\
ACS54263 & Japan & $2009 / 06 / 09$ & S220T \\
ACS54301 & China & $2009 / 05 / 28$ & S220T \\
ACT10838 & China & $2009 / 05 / 20$ & - \\
ACS68822 & China & $2009 / 05 / 31$ & E117G, S220T, V428I \\
\hline
\end{tabular}

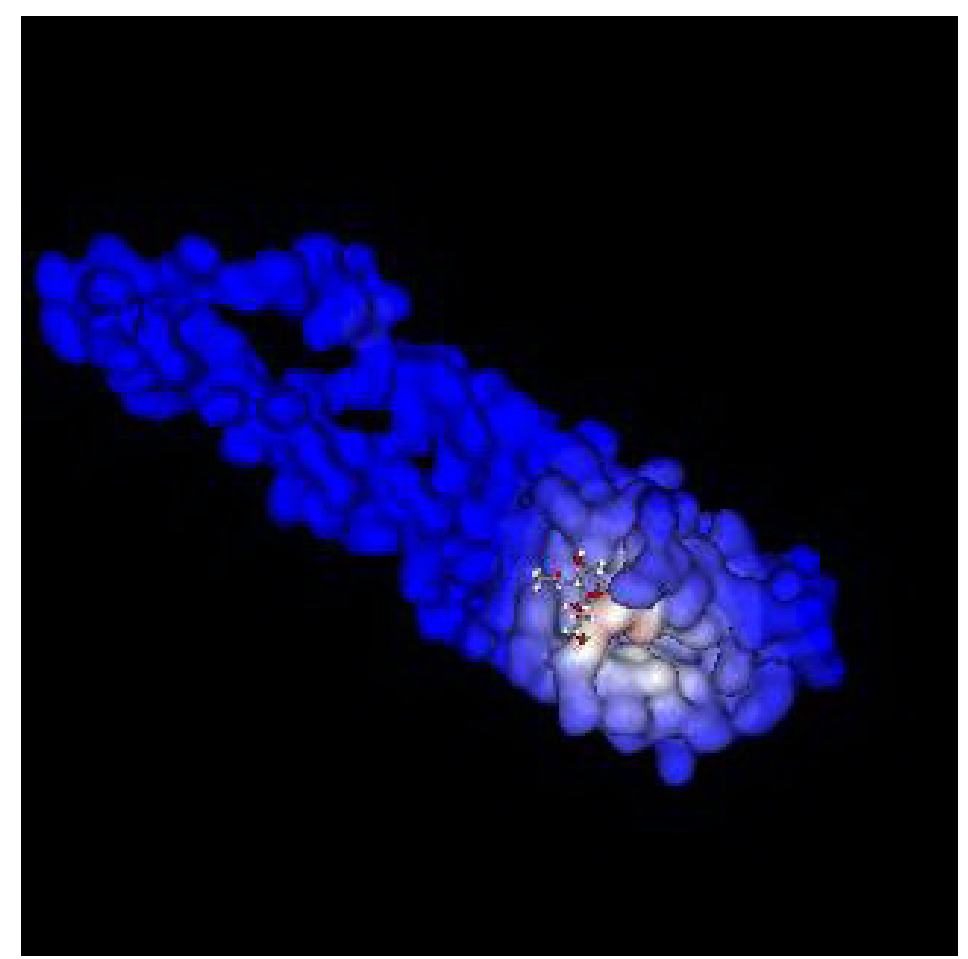

Figure 1. Interaction between sialic acid (SA) and the monomer HA protein of influenza virus A (H1N1). This is the top view of the docking results. The HA protein model is shown in CPK format (blue). The SA is shown in ball and stick format. 


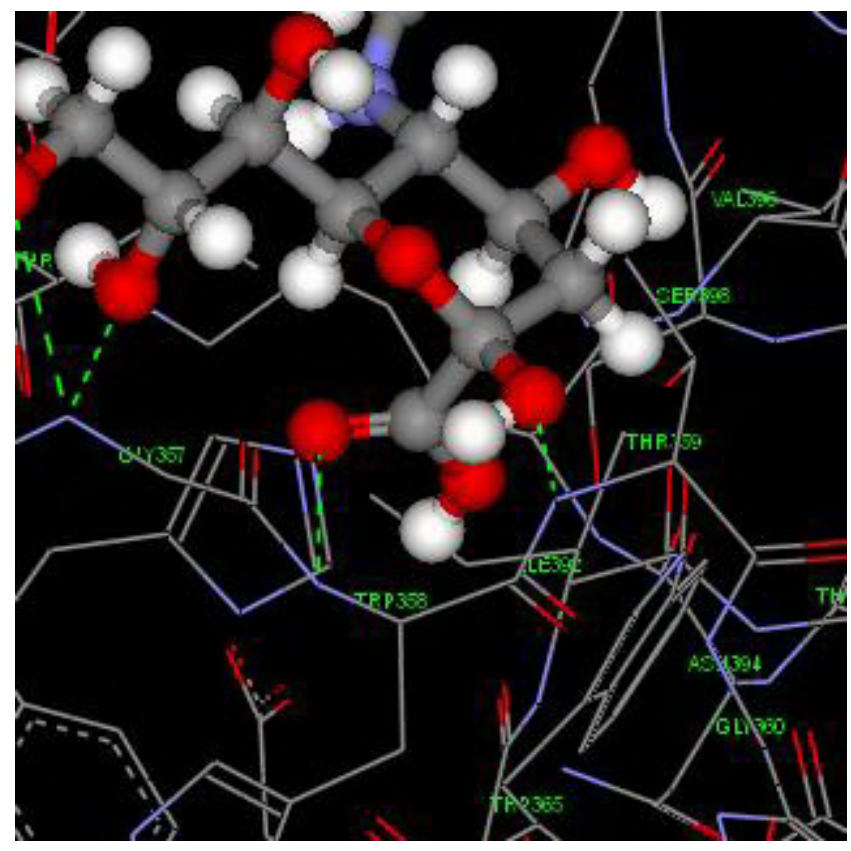

Figure 2. Intermolecule interaction between the HA protein of H1N1 and o-SA. The model shows strong hydrogen bonding between the ligand and the HA protein at positions GLY357, TRP358 and THR359.

\section{DISCUSSION}

Influenza pandemics occur when an influenza virus with an HA emerges in the human population and is efficiently transmitted from human to human (Garten et al., 2009). Sixteen subtypes of HA have been identified and the influenza A (H1N1) is the influenza A virus with the HA subtype H1. HA is located outside the virus membrane. In our study, the majority of HA proteins of the 86 influenza A (H1N1) viruses isolated from Asian patients indicated stability in their sequence during this pandemic by only having a few amino acid changes. There was no major mutation, which can possibly change the affinity of HA to human receptors and consequently alter the virulence of influenza A (H1N1). Hence, if the pandemic gets worse in the second wave, it is most likely not only because of HA mutation, that is, NA is the other protein that we need to study. Notably, resistance to oseltamivir has been reported in many countries, and it can occur by only single amino acid substitution in the enzyme NA (Ward et al., 2005). Likewise, close monitoring of viruses by a WHO network of laboratories also shows that viruses from all outbreaks remain virtually identical. No signs of virus mutation to a more virulent or lethal form have been detected (Turner et al., 2009).

In general, a complete HA protein segment is a homotrimer and shaped like a cylinder. It is approximately $13.5 \mathrm{~nm}$ long. Each HA monomer is synthesized as a single polypeptide that is cleaved by proteases into two subunits (HA1 and HA2). HA1 contains the receptorbinding and antigenic domains, whereas the HA2 subunit is responsible for the fusion of the virion with the endosomal membrane in the host cell (Wilson and Cox 1990). The HA1 
subunit undergoes a process known as positive Darwinian selection through continuous antigenic mutations that allows the virus to evade the host's humoral immune response (Fitch et al., 1991). The 3 spherical heads of HA bind to receptors containing glycans with terminal SAs on the cell surface in the respiratory tract, where their precise linkage determines species preference (Stevens et al., 2006). Our study demonstrated a perfect binding of HA of influenza A (H1N1) virus to human o-SA via hydrogen bonding (Figures 1 and 2). Amino acid substitutions within the receptor-binding pocket or the "second shell" residues may alter the specificity and affinity of the influenza A virus HA toward certain types of galactosidic linkages, namely SA- $\alpha 2,3$-galactose (SA $\alpha 2,3 \mathrm{Gal}$ ) (avian) or SA $\alpha 2,6 \mathrm{Gal}$ (human) linkages (Aytay and Schulze, 1991; Matrosovich et al., 2000). In the human respiratory tract, the SAs most dominantly expressed are those linked with SA $\alpha 2,6 \mathrm{Gal}$ (upper airway) and SA $\alpha 2,3 \mathrm{Gal}$ (alveoli and the terminal bronchiole) (Shinya et al., 2006). The affinity of HA attachment to SA is deemed a crucial component in the species barrier that keeps avian influenza viruses from readily infecting humans (Nicholls et al., 2009). Both avian and human-like SAs are present in pig respiratory epithelium and can be infected with both human and avian influenza viruses. Thus, pig becomes the "mixing vessel" where reassortment of avian and human viruses can take place, potentially leading to the emergence of novel influenza strains and causing pandemics (Ito et al., 1998). A very good example of this situation is the currently occurring swine influenza A (H1N1) pandemic, whereby the speed of transmission and fatality number of the infection are considerably alarming. Overall, the HA protein of influenza A(H1N1) virus can bind to human SA and lead to infection. No major mutation was observed in the HA sequence among viruses isolated from Asian patients during this outbreak.

\section{REFERENCES}

Arnold K, Bordoli L, Kopp J and Schwede T (2006). The SWISS-MODEL workspace: a web-based environment for protein structure homology modelling. Bioinformatics 22: 195-201.

Aytay S and Schulze IT (1991). Single amino acid substitutions in the hemagglutinin can alter the host range and receptor binding properties of $\mathrm{H} 1$ strains of influenza A virus. J. Virol. 65: 3022-3028.

Brankston G, Gitterman L, Hirji Z, Lemieux C, et al. (2007). Transmission of influenza A in human beings. Lancet Infect. Dis. 7: 257-265.

Carrat F, Vergu E, Ferguson NM, Lemaitre M, et al. (2008). Time lines of infection and disease in human influenza: a review of volunteer challenge studies. Am. J. Epidemiol. 167: 775-785.

Centers for Disease Control and Prevention (CDC) (2009). Swine influenza A (H1N1) in two children - southern California, March-April 2009. MMWR Morb. Mortal. Wkly. Rep. 58: 400-402.

Centers for Disease Control and Prevention (CDC) (2010). Interim results: influenza A (H1N1) 2009 monovalent vaccination coverage - United States, October-December 2009. MMWR Morb. Mortal. Wkly. Rep. 59: 44-48.

Fitch WM, Leiter JM, Li XQ and Palese P (1991). Positive Darwinian evolution in human influenza A viruses. Proc. Natl. Acad. Sci. U. S. A. 88: 4270-4274.

Garten RJ, Davis CT, Russell CA, Shu B, et al. (2009). Antigenic and genetic characteristics of swine-origin 2009 A(H1N1) influenza viruses circulating in humans. Science 325: 197-201.

Guex N and Peitsch MC (1997). SWISS-MODEL and the Swiss-PdbViewer: an environment for comparative protein modeling. Electrophoresis 18: 2714-2723.

Ito T, Couceiro JN, Kelm S, Baum LG, et al. (1998). Molecular basis for the generation in pigs of influenza A viruses with pandemic potential. J. Virol. 72: 7367-7373.

Matrosovich M, Tuzikov A, Bovin N, Gambaryan A, et al. (2000). Early alterations of the receptor-binding properties of $\mathrm{H} 1, \mathrm{H} 2$, and $\mathrm{H} 3$ avian influenza virus hemagglutinins after their introduction into mammals. J. Virol. 74: 8502-8512.

National Center for Biotechnology Information (NCBI) (2009). Influenza Virus Resource. Available at [http://www.ncbi. nlm.nih.gov/genomes/FLU/Database/select.cgi?go=1]. Accessed August 31, 2009.

Nicholls JM, Peiris JS and Guan Y (2009). Sialic acid and receptor expression on the respiratory tract in normal subjects 
and H5N1 and non-avian influenza patients. Hong Kong Med. J. 15: 16-20.

Novel Swine-Origin Influenza A (H1N1) Virus Investigation Team (2009). Emergence of a novel swine-origin influenza A (H1N1) virus in humans. N. Engl. Med. 360: 2605-2615.

Schwede T, Kopp J, Guex N and Peitsch MC (2003). SWISS-MODEL: An automated protein homology-modeling server. Nucleic Acids Res. 31: 3381-3385.

Shinya K, Ebina M, Yamada S, Ono M, et al. (2006). Avian flu: influenza virus receptors in the human airway. Nature 440: 435-436.

Stevens J, Blixt O, Tumpey TM, Taubenberger JK, et al. (2006). Structure and receptor specificity of the hemagglutinin from an H5N1 influenza virus. Science 312: 404-410.

Swedish KA, Conenello G and Factor SH (2010). First season of 2009 H1N1 influenza. Mt. Sinai J. Med. 77: 103-113.

Trifonov V, Khiabanian H and Rabadan R (2009a). Geographic dependence, surveillance, and origins of the 2009 influenza A (H1N1) virus. N. Engl. J. Med. 361: 115-119.

Trifonov V, Khiabanian H, Greenbaum B and Rabadan R (2009b). The origin of the recent swine influenza A(H1N1) virus infecting humans. Euro Surveill. 14: pii=19193.

Turner SJ, Brown LE, Doherty PC and Kelso A (2009). Q\&A: What have we found out about the influenza A (H1N1) 2009 pandemic virus? J. Biol. 8: 69.

Ward P, Small I, Smith J, Suter P, et al. (2005). Oseltamivir (Tamiflu) and its potential for use in the event of an influenza pandemic. J. Antimicrob. Chemother. 55: i5-i21.

White JM, Hoffman LR, Arevalo JH and Wilson IA (1997). Attachment and Entry of Influenza Virus Into Host Cells. Pivotal Roles of Hemagglutinin. In: Structural Biology of Viruses (Chiu W, Burnett RM and Garcea RL, eds.). Oxford University Press, Oxford, 80-104.

Wilson IA and Cox NJ (1990). Structural basis of immune recognition of influenza virus hemagglutinin. Annu. Rev. Immunol. 8: 737-771. 